\title{
O Ciclo Heiner Müller na Casa Conveniente
}

\section{Rui Monteiro}
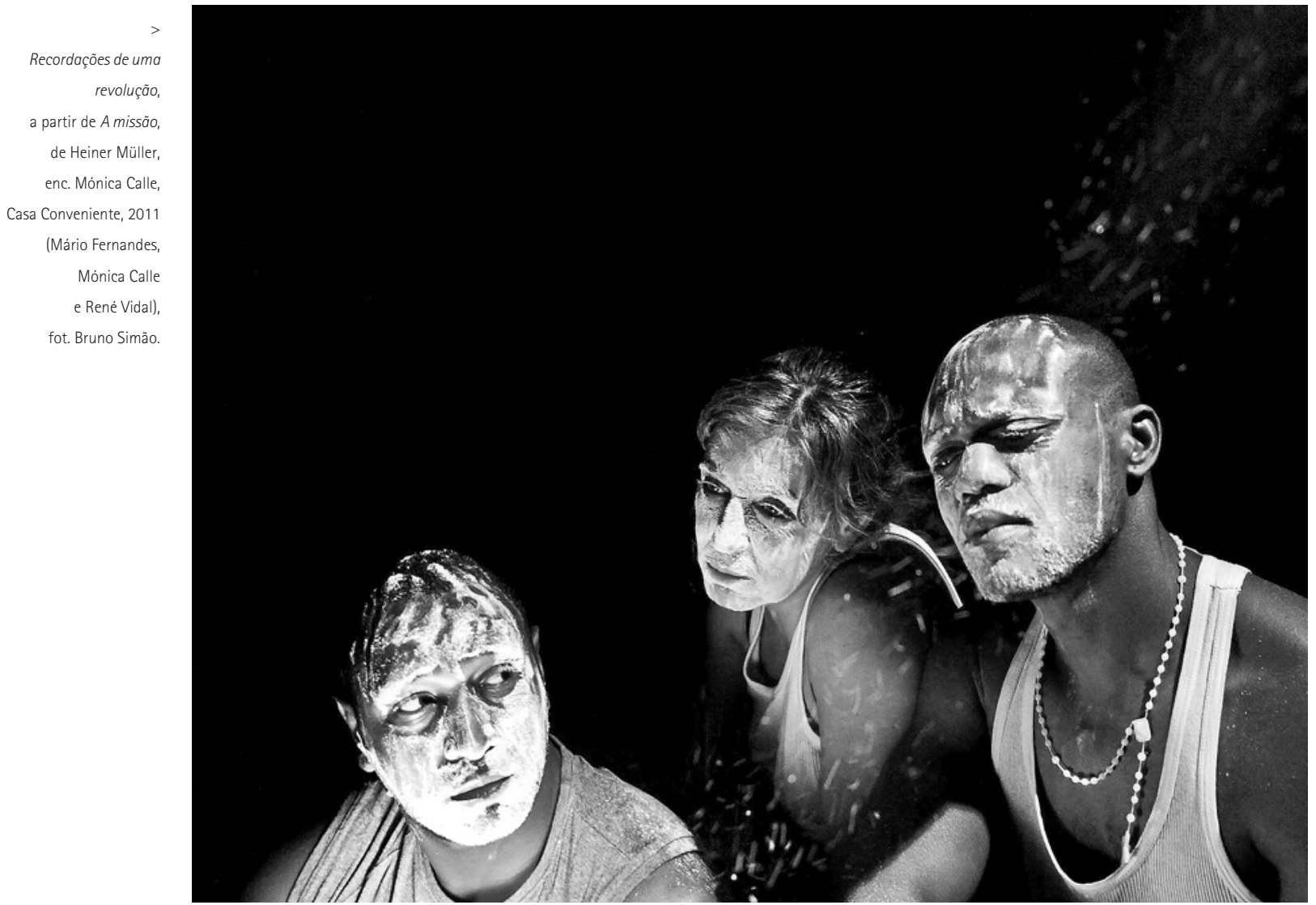

Por vezes, assistir a um espectáculo de teatro é como entrar na gruta do dragão sem escudo de amianto, nem lança de titânio, nem plano de retirada. Sabe-se mais ou menos ao que se vai, encontram-se métodos conhecidos, reconhecem-se sinais, mas não se escapa sem se ser lambido pelas chamas. Por isso, a indiferença não é uma possibilidade perante um espectáculo da Casa Conveniente, um desses dragões benignos que regularmente abrem a sua gruta para jogarem mãos cheias de interrogações. Porque é de interrogação, a começar logo pela dos próprios textos que trabalham, que se faz no Cais do Sodré aquele teatro intimo, minimalista e um pouco iniciático.

No ciclo do ano passado dedicado à obra de Heiner Müller, tudo começou com Anúncio de morte, três solos a partir de originais do dramaturgo alemão: Álbum de família releitura de Máquina-Hamlet, Sete espelhos no quarto de dormir, nascido de Descrição de um quadro, e O passeio das raparigas mortas, inspirado em Anúncio de morte.
Depois chegou Recordações de uma revolução, dramaturgia originária de A missão; mais tarde Macbeth, pelo meio, David Pereira Bastos interrompendo a sequência de encenações de Mónica Calle com Titus: Laboratório de sangue.

Bem se pode dizer que montar estas peças é participar de uma utopia sem devir, mas que ainda assim resiste. Pois apesar de tudo revelado e oculto, dito ou intuido, iluminado e obscuro, o ambiente de "derrotismo construtivo" criado pelos espectáculos de Mónica Calle a partir do teatro de lúcida crueldade de Müller, inclui uma réstia de esperança. Se preferirem, uma vontade - não um desejo nostálgico - de dançar a revolução. Entrar na gruta do dragão é, afinal, partilhar um teatro atento à realidade e às suas complexidades e armadilhas. Um teatro disponível para se interrogar tanto como questionar os outros, consciente da necessidade de repensar ideias e práticas, traduzindo em acção um desejo de intervenção e cidadania. 

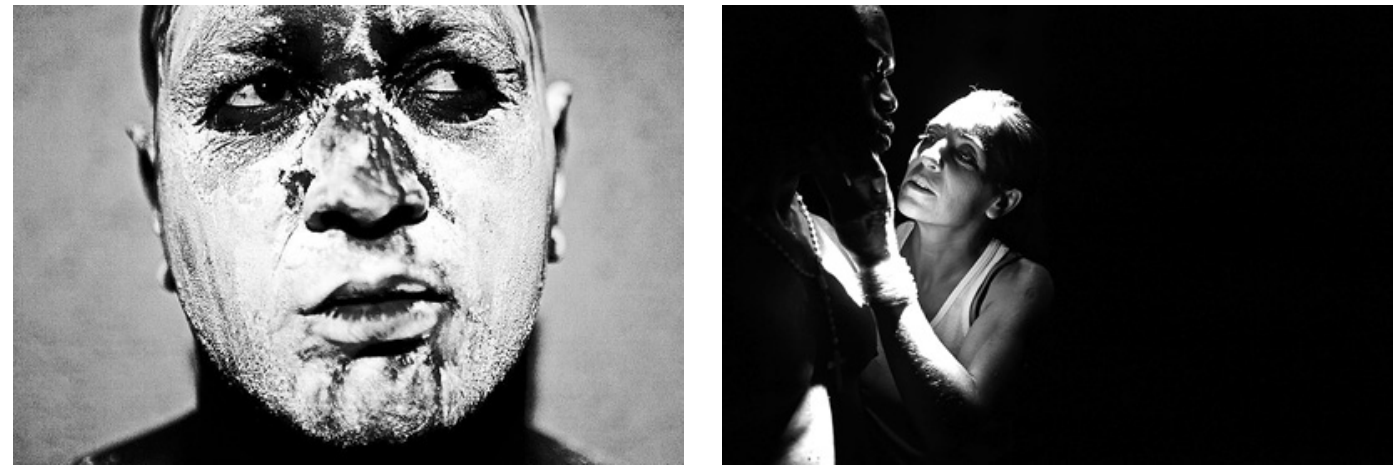

$<>$

$\checkmark$

Recordações de uma

revolução,

a partir de $A$ missão,

de Heiner Müller,

enc. Mónica Calle,

Casa Conveniente, 201

(< Mário Fernandes;

$>$ René Vidal

e Mónica Calle;

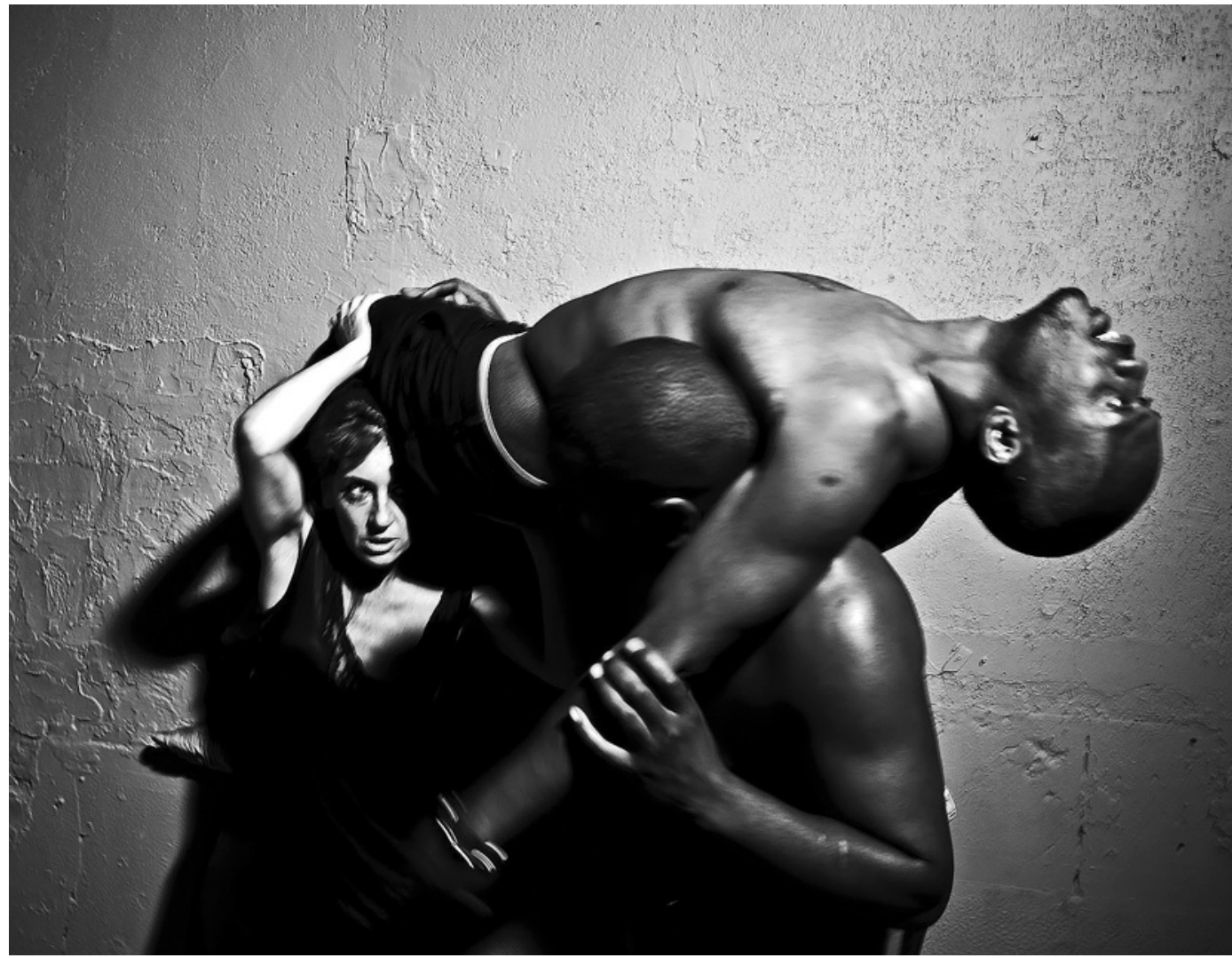

v Mário Fernandes,

Mónica Calle

e René Vidal),

fot. Bruno Simão.

Diz a Teoria do Caos que a natureza encontra sempre uma maneira de prevalecer, resistindo e sobrevivendo seja qual for a dimensão da catástrofe. Pois bem, a Casa Conveniente é a erva que desponta no meio do asfalto, como uma insurreição, entre o trânsito de imagens fúteis e de ideias parvas, recordando o essencial. Foi assim, mais uma vez, em 2011, com o ciclo dedicado à obra de Heiner Müller, razão desta Menção Especial do júri da Associação Portuguesa de Críticos de Teatro. É assim ao longo do seu trajecto feito tanto de desejo como de indignação. De resignação, não. 